\title{
Gene Expression of Peroxisome Proliferator-Activated Receptor Is Upregulated by Nonsteroidal Anti-Inflammatory Drugs and Correlates with Cyclooxygenase-2 Suppression In Inflamed-Rat Muscle
}

\author{
Abdelhady $\mathrm{S}^{1}$, El Ashmawy $\mathrm{N}^{2}$, El Bahrawy $\mathrm{H}^{3}$, Fouad $\mathrm{H}^{4}$ \\ ${ }_{1,2,3,4}$ (Biochemistry, Phaculty of Parmacy/Pharos University, Egypt)
}

\begin{abstract}
The peroxisome proliferator-activated receptors (PPARs) have been implicated in the regulation of endothelial cell inflammatory response. The purpose of the present study was to clarify the molecular mechanism of NSAIDs in controlling inflammation regarding the gene expression of PPAR $\alpha$ and PPAR $\gamma 1$ in a rat model of chronic inflammation. Wistar rats were classified into 5 experimental groups; 9 rats each. Group (1) normal control; group (2) injected s.c. with $0.3 \%$ carrageenan in muscle on days 1, 4 and 7 . Groups (3, 4 and 5) were injected s.c. with carrageenan and at the same time given orally $10 \mathrm{mg} / \mathrm{Kg}$ Celecoxib, $12.5 \mathrm{mg} / \mathrm{Kg}$ Nimesulide or $10 \mathrm{mg} / \mathrm{Kg}$ sulindac, respectively. On day 7, edema was measured before scarification. Gene expression PPAR 1 and PPAR $\alpha$ was measured in rat muscle by RT-PCR. COX-2 was analyzed in rat muscle by ELISA. Celecoxib produced the greatest \% inhibition of carrageenan-induced edema. PPAR $\gamma 1$ and PPAR $\alpha$ gene expression were significantly increased by NSAIDs treatment compared with carrageenan-untreated group. The inhibition of COX-2 together with upregulation of PPAR $\alpha$ and PPAR $\gamma 1$ nominate NSAIDs to be promising candidates for pharmacologic treatment of tumorgenesis.
\end{abstract}

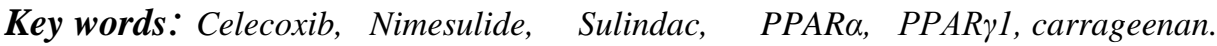

\section{Introduction}

Chronic inflammation is defined as inflammation of prolonged duration in which active inflammation, tissue destruction and attempts at healing are proceeding simultaneously (1). Chronic inflammation results in either repair by fibrosis or granuloma formation (2). Nonsteroidal anti-inflammatory drugs (NSAIDs) are cyclooxygenase (COX) inhibitors frequently used in the treatment of acute and chronic inflammation. Side effects of NSAIDs are often due to their ability to induce apoptosis, gastric and duodenal ulcers and cytotoxicity in liver cells (3). The inhibition of COX-1 is responsible for the adverse effects of traditional NSAIDs (as sulindac) on the gastrointestinal mucosa, while their therapeutic benefits depend on the inhibition of COX-2. Therefore, COX-2 selective inhibitors (as Celecoxib and Nimesulide) were developed to reduce the adverse effects produced from the inhibition of COX-1 by conventional NSAIDs (4).

The peroxisome proliferator-activated receptors (PPARs) belong to the group of nuclear receptor superfamily. There are three subtypes of these receptors, PPAR $\alpha, \operatorname{PPAR} \beta / \delta$, and PPAR $\gamma$. PPARs mainly regulate lipid and carbohydrate metabolism (5). These receptors are also involved in inflammatory process, reproduction, carcinogenesis and other physiological processes in the body. PPAR activation inhibits inflammatory response genes and decreases the production of inflammatory mediators like IL-6, IL-2, TNF $\alpha$, and COX-2, and also suppresses cells like T cell and macrophages. PPAR $\alpha$ and PPAR $\gamma$ have been implicated in the regulation of endothelial cell inflammatory response and induction of apoptosis (6).

A wide variety of natural and synthetic compounds was identified as PPAR ligands. Among the synthetic ligands, the lipid lowering drugs; fibrates, and the insulin sensitizers; thiazolidinediones are PPAR $\alpha$ and PPAR $\gamma$ agonists, respectively, which underscores the important role of PPARs as therapeutic targets (7). Interestingly, indomethacin and other NSAIDs that inhibit the production of prostaglandins are also able to activate PPAR $\alpha$ and PPAR $\gamma(\mathbf{8})$.

The purpose of the present study was to clarify the molecular mechanism of NSAIDs in controlling inflammation regarding the gene expression of PPAR $\alpha$ and PPAR $\gamma 1$ in a rat model of chronic inflammation. The relation between COX-2 inhibition and PPARs expression in rat muscle was also investigated.

\section{Materials and Methods}

Forty five Wistar rats (male and female), weighing 120-160 g, were utilized in the present study. The rats were obtained from the animal house of Faculty of Pharmacy and Drug Manufacturing, Pharos University, Alexandria. The animals were maintained in plastic cages at $25^{\circ} \mathrm{C}$ in animal house for two weeks for acclimatization and were allowed free access to water and food. The rats were fed bread and milk. 
Gene expression of peroxisome proliferator-activated receptor is upregulated by nonsteroidal anti-

Rats were classified into 5 experimental groups; 9 rats each. Group 1: normal control group given the vehicle (polyethyleneglycol 400/saline 2:1 v/v, El-Amria and El-Nasr Companies). Group 2: inflammation control group injected s.c. with carrageenan (Sigma-Aldrich Inc. USA) $0.3 \%$ in saline (9) on days 1, 4 and 7 (10). Group 3: Celecoxib group administered Celecoxib (El-Amria Company) $10 \mathrm{mg} / \mathrm{Kg}$ bw orally daily (11). Group 4: Nimesulide group administered Nimesulide (Cayman Chemical Co. USA) $12.5 \mathrm{mg} / \mathrm{Kg}$ bw orally daily (12). Group 5: Sulindac group administered Sulindac (Cayman Chemical Co. USA) $10 \mathrm{mg} / \mathrm{Kg}$ bw orally daily (13). Rats of groups 3, 4, 5 were subjected to carrageenan injection as in group 2 on days 1,4 and 7 , whereas the administration of drugs continued from day 1 to day 7 .

Four hours after the $3^{\text {rd }}$ injection of carrageenan, the edema was measured by caliber around the rat muscle of the carrageenan-treated leg. Twenty four hours after last treatment, the rats were sacrificed by cervical dislocation and then dissected. The gastrocnemius muscle was divided into three portions and kept at $-80^{\circ} \mathrm{C}$. The first portion was used for measurement of gene expression of PPAR $\alpha$ (14) and PPAR $\gamma 1$ (15) by reverse transcriptase polymerase chain reaction (RT-PCR). The second portion was used to measure COX-2 by enzyme-linked immunosobent assay (ELISA) (16). The third portion was embedded in 10\% formaline (El-Gomhoria Chemical Company, Egypt) and utilized for histopathological examination.

\subsection{Reverse transcriptase PCR}

Total RNA was extracted from frozen muscle using Total RNA Extraction Kit (Bioer Technology, China). RNA $(1 \mu \mathrm{g})$ was reverse transcribed to give complementary DNA (cDNA) according to the manufacturer's instructions (The ProtoScript ${ }^{\circledR}$ AMV, First Strand cDNA Synthesis Kit, New England Biolabs, Inc.). cDNA was PCR amplified using $0.05 \mathrm{U} / \mu \mathrm{L}$ Taq DNA polymerase in a thermal cycler (Little Genius, Bioer, Germany). The Primers for amplification of PPAR- $\gamma 1$ gene: (Forward): 5'TGCTGGTGATCAGAAGGCTG3'. (Reverse): 5'ACGCAGGCTCTACTTTGAT CG-3'. The Primers for amplification of PPAR- $\alpha$ gene: (Forward): 5'-TGCATGTCCGTGGAGACCGTCAC-3'. (Reverse): 5'ACTCGGTCTTCTTGAT GACC-3'. Initial pre-denaturation temperature was $94^{\circ} \mathrm{C}$ for $1 \mathrm{~min}$ for one cycle. After that 35 cycles of the following program were carried out: denaturation step was at $94{ }^{\circ} \mathrm{C}$, for 1 min for the two genes. Annealing step was $55^{\circ} \mathrm{C}(1 \mathrm{~min})$ for PPAR $\gamma 1$ and was $51^{\circ} \mathrm{C}(1 \mathrm{~min})$ for PPAR $\alpha$. Extension step was $72^{\circ} \mathrm{C}(1 \mathrm{~min})$ for the two genes, and a final extension step was carried out at $72^{\circ} \mathrm{C}(5-7 \mathrm{~min})$.

The PCR product was then loaded onto $3 \%$ agarose (Sigma-Aldrich Inc. USA) gel stained with ethidium bromide (Biobasic Inc. Canada) and the bands on the gel were visualized using UV transilluminator (Uvitec, EEC). The intensity of DNA bands were measured by photoshop version 7.

\subsection{Measurement of COX-2 by ELISA}

Citrate buffer ( $\mathrm{pH} 5.5)$ was added to the muscle tissue (2:1) (v/w), which was then homogenized, then centrifuged for $10 \mathrm{~min}$ at 13,000 rpm (Baujahr centrifuge, Germany). The supernatant was used for estimation of COX-2 by ELISA using Rat COX-2 assay kit-IBL (Immuno-Biological Laboratories Co., Ltd.). The concentration of COX-2 in rat muscle was obtained from a preconstructed standard curve and was expressed as $\mathrm{ng} / \mathrm{g}$ tissue.

\subsection{Histopathological examination of rat muscle}

The gastocnemius muscles were fixed in $10 \%$ formaline overnight. The tissues were dehydrated with alcohol then cleared in xylene. The tissues were embedded in warm paraffin wax, after cooling; the tissue hardens (blocks), and can be used to cut slices (sectioned). $4 \mu \mathrm{m}$ sections were stained with hematoxylin \& eosin (H\&E). Then sections were investigated under light microscope (Olympus PX-41, Tokyo, Japan) using image analysis system under magnification X400. The tissues were investigated by a pathologist for the number of inflammatory cells present. The inflammation was evaluated as mild inflammation (+), moderate inflammation $(++)$ or severe inflammation $(+++)$.

\subsection{Statistical analysis:}

Data were fed to the computer using the Predictive Analytics Software (PASW Statistics 18). Quantitative data were described using mean and standard error. The comparison between two independent populations was done using independent t-test. Correlations between two quantitative variables were assessed using Pearson coefficient. Significance test results are quoted as two-tailed probabilities. Significance of the obtained results was judged at the $5 \%$ level.

\section{Results}

3.1 Effect of NSAIDs on carrageenan-induced edema in rat muscle

Subcutaneous injection of $100 \mu \mathrm{L}$ of $0.3 \%$ carrageenan solution into gastocnemius muscle of rats resulted in edema formation. Treatment with Celecoxib, Nimesulide and Sulindac inhibited edema. The percent inhibition was $64.32 \pm 5.13 \%$ for Celecoxib, $61.43 \pm 8.55 \%$ for Nimesulide and $48.67 \pm 3.97 \%$ for Sulindac. 
Gene expression of peroxisome proliferator-activated receptor is upregulated by nonsteroidal anti-

Celecoxib treatment significantly inhibited edema compared with Sulindac group. The anti-inflammatory activity of NSAIDs in the descending order was as follows: Celecoxib > Nimesulide > Sulindac (Fig. 1).

\subsection{Effect of NSAIDs on gene expression of PPAR $\gamma 1$ and PPAR $\alpha$ in rat muscle}

The RT-PCR products of amplified PPAR $\gamma 1$ gene and PPAR $\alpha$ gene were separated by gel electrophoresis where the bands of PPAR $\gamma 1$ appeared at $373 \mathrm{bp}$ (Figure 2) and the bands of PPAR $\alpha$ gene appeared at 523bp (Fig. 3). PPAR $\gamma 1$ gene expression showed significant decrease in carrageenan untreated group ( $\mathrm{p}<0.05$ ) compared with normal control group (Fig. 4). The studied NSAIDs exhibited a significant increase in PPAR $\gamma 1$ gene expression $\quad(\sim 26.45 \% \uparrow, \simeq 18.9 \% \uparrow$ and $\simeq 62.35 \% \uparrow, p<0.05)$ in Celecoxib, Nimesulide and Sulindac group, respectively, compared with carrageenan untreated group (Fig. 4).

Treatment with Sulindac resulted in a significant increase in PPAR $\gamma 1$ gene expression versus each of Celecoxib group, Nimesulide group, and control group (Fig. 4).

PPAR $\alpha$ gene expression significantly decreased in carrageenan untreated rats $(\mathrm{p}<0.05)$ compared with normal control rats. The selected NSAIDs exhibited a significant increase in PPAR $\alpha$ gene expression $(\simeq 26.6 \% \uparrow, 18.5 \%$ $\uparrow$ and $\simeq 21.5 \% \uparrow, p<0.05)$ in Celecoxib, Nimesulide and Sulindac group, respectively, compared with carrageenan untreated group (Fig. 5).

\subsection{Effect of NSAIDs on COX-2 level in rat muscle}

Carrageenan untreated group showed significant increase in COX-2 level $(\mathrm{p}<0.05)$ compared with normal control group. Each of Celecoxib and Nimesulide produced a significant decrease $(p<0.05)$ in COX-2 level compared with carrageenan group. Sulindac treatment exhibited a significant increase in COX-2 level versus each of Celecoxib and Nimesulide groups $(\mathrm{p}<0.05)$. COX-2 level in the NSAID-treated rats did not return to its level in the normal control group (Table 1).

\subsection{Correlation study:}

The correlation study revealed that there was a significant positive correlation between gene expression of muscle PPAR $\alpha$ and gene expression of muscle PPAR $\gamma 1(p=0.012$, Figure 6). A significant negative correlation was observed between gene expression of muscle PPAR $\alpha$ and each of muscle COX-2 ( $\mathrm{p}=$ 0.01 , Figure 7) and edema $(p=0.005$, Figure 8$)$. A significant negative correlation was found between gene expression of muscle PPAR $\gamma 1$ and edema $(\mathrm{p}=0.24$, Fig. 9).

\subsection{Histopathological examination of rat muscle}

Normal control group showed normal muscle fibers without inflammation (Figure 10A). Carrageenaninflamed muscle showed moderate (++) to severe (+++) inflammation in between muscle fibers in the form of leukocytes, also there is dilatation and thickening of blood vessels (Fig. 10B).

Celecoxib treated rats showed mild $(+)$ inflammation as the number of leukocytes was less than its number in carrageenan untreated group. The muscle fibers are normal without necrosis (Fig. 10C). Nimesulide treated rats showed mild $(+)$ to moderate $(++)$ inflammation with tissue granulation; the muscle is intact without necrosis (Fig. 10D). Sulindac treated rats showed moderate (++) to severe (+++) inflammation. Inflammatory cells present in between muscle fibers with thickening and proliferation of blood vessels (Fig. 10E).

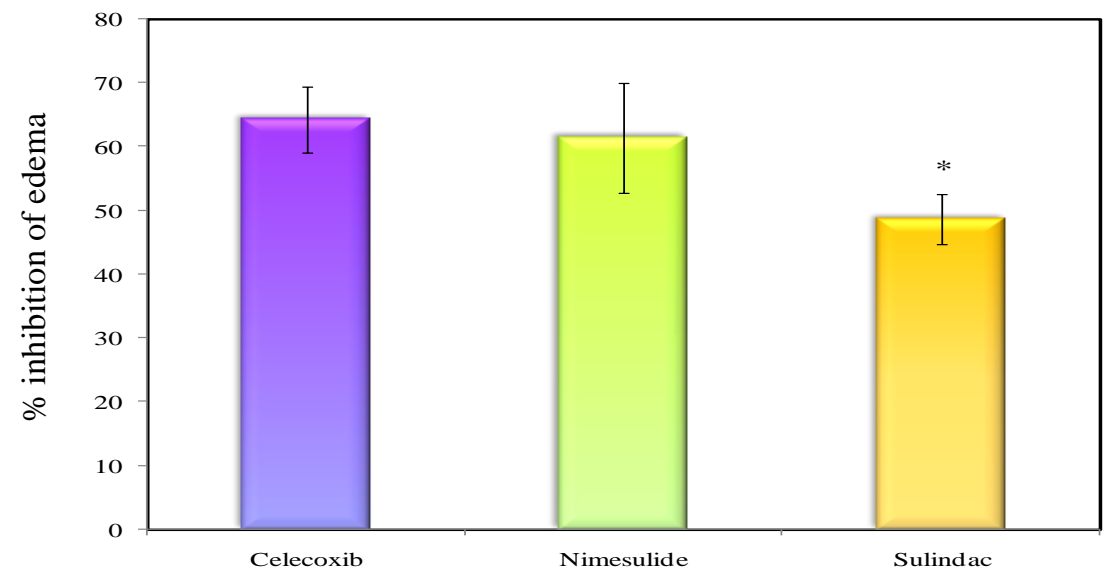

Figure (1): Effect of NSAIDs on carrageenan-induced edema in rat muscle

Data are presented as mean \pm SEM, $n=9$ for each group, $*$ : significant versus Celecoxib 
Gene expression of peroxisome proliferator-activated receptor is upregulated by nonsteroidal anti-

Table (1): Effect of NSAIDs on COX-2 level in rat muscle

\begin{tabular}{|c|c|c|c|c|c|}
\hline Groups & $\begin{array}{c}\text { Normal } \\
\text { control }\end{array}$ & Carrageenan & Celecoxib & Nimesulide & Sulindac \\
\hline $\begin{array}{c}\text { COX-2 } \\
(\mathbf{n g} / \mathbf{g})\end{array}$ & $\begin{array}{c}10.67 \\
\pm 2.40\end{array}$ & $\begin{array}{c}23.53^{\mathrm{a}} \\
\pm 1.83\end{array}$ & $\begin{array}{c}16.32^{\mathrm{ab}} \\
\pm 0.66\end{array}$ & $\begin{array}{c}18.25^{\mathrm{ab}} \\
\pm 0.48\end{array}$ & $\begin{array}{c}23.20^{\mathrm{acd}} \\
\pm 1.14\end{array}$ \\
\hline
\end{tabular}

Data are presented as mean \pm SEM; $\mathrm{n}=9$ for each group

a: Significant versus control group

b: Significant versus carrageenan group

c: Significant versus celecoxib group

$\mathrm{d}$ : Significant versus nimesulide group

(A)

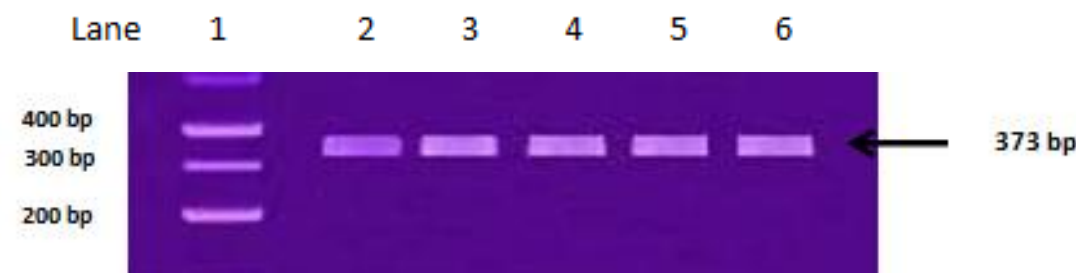

(B)

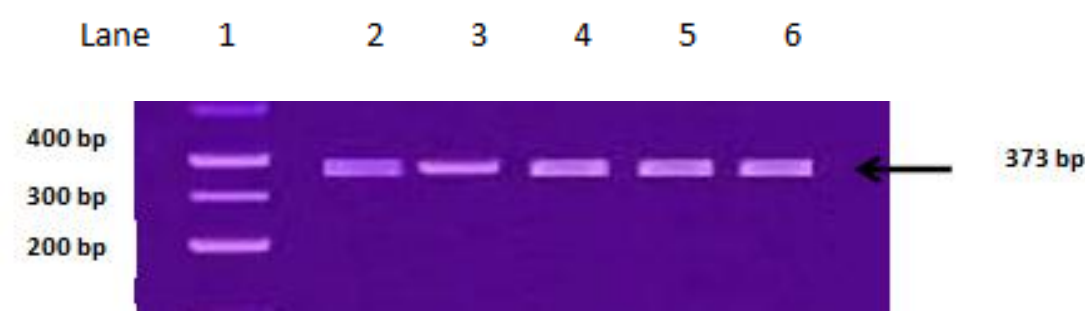

(C)

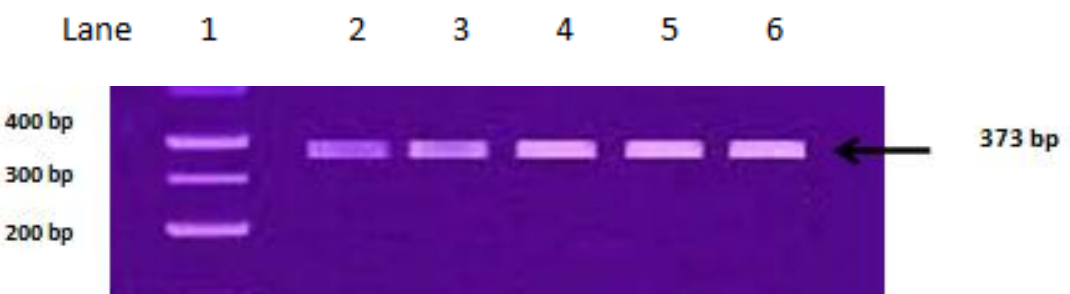

Figure (2): Ethidium bromide stained agarose gel showing bands of amplified PCR products of PPAR $\square \mathbf{1}$ gene of rat muscle. Lane 1: DNA marker, lane 2: carrageenan group, lane 3: normal control group, lanes 4, 5 and 6: NSAIDs-treated groups: (A) Celecoxib group, (B) Nimesulide group and (C) Sulindac group. Each lane represents pooled sample of muscles of three different rats. 
(A)
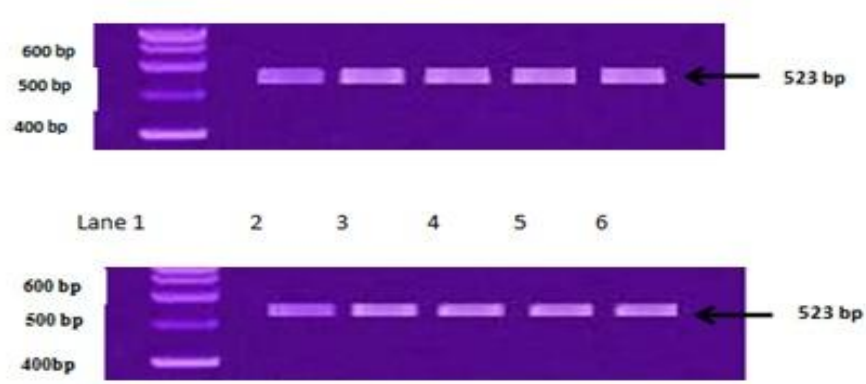

(C)

$\begin{array}{lllllll}\text { Lane } 1 & 2 & 3 & 4 & 5 & 6\end{array}$

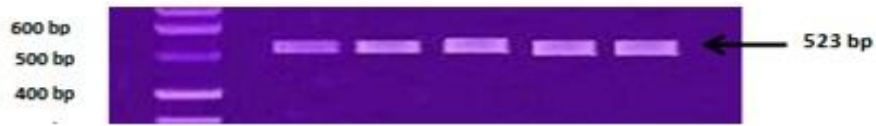

Figure (3): Ethidium bromide stained agarose gel showing bands of amplified PCR products of PPAR $\square$ gene of rat muscle. Lane 1: DNA marker, lane 2: carrageenan group, lane 3: normal control group, lanes 4, 5 and 6: NSAIDs-treated groups: (A) Celecoxib group, (B) Nimesulide group and (C) Sulindac group. Each lane represents pooled sample of muscles of three different rats.

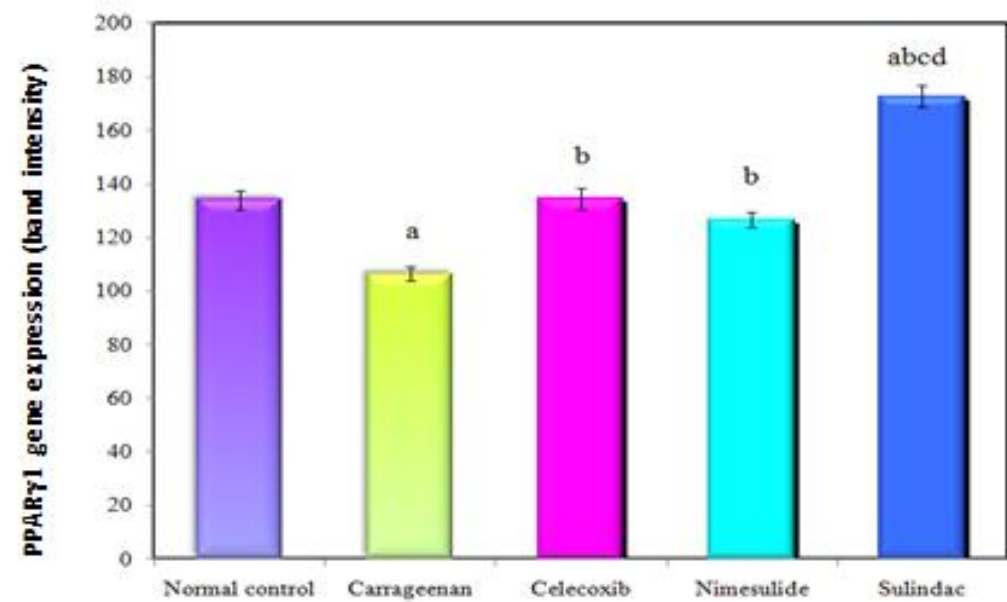

Figure (4): Effect of NSAIDs on PPAR $\gamma 1$ gene expression in rat muscle

Data are presented as mean $\pm S E M ; n=9$ rats for each group

a: Significant versus normal control group

b: Significant versus carrageenan group

c: Significant versus celecoxib group

d: Significant versus nimesulide group 


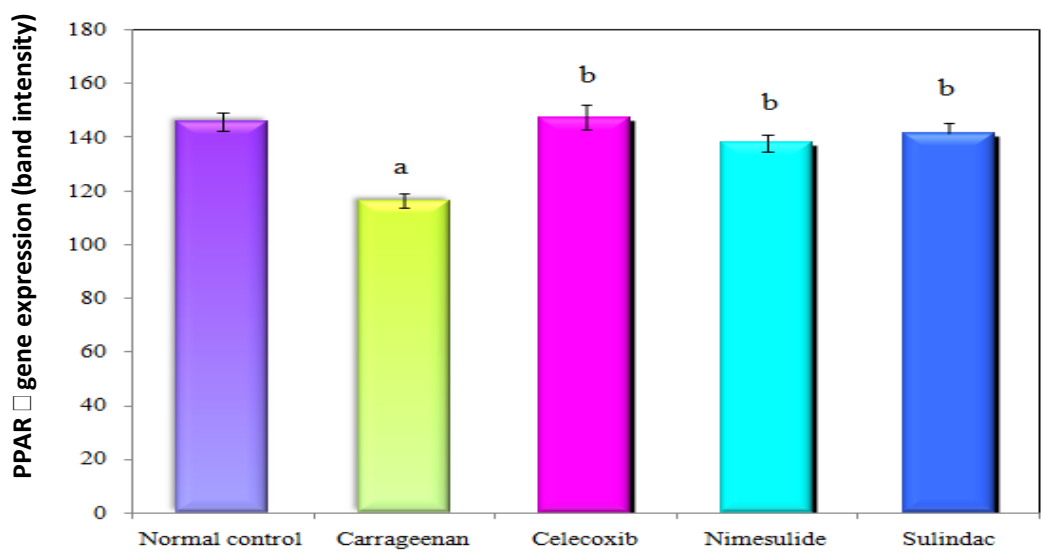

Figure (5): Effect of NSAIDs on PPAR $\alpha$ gene expression in rat muscle

Data are presented as mean $\pm \mathrm{SEM} ; \mathrm{n}=9$ rats for each group a: Significant versus normal control group b: Significant versus carrageenan group

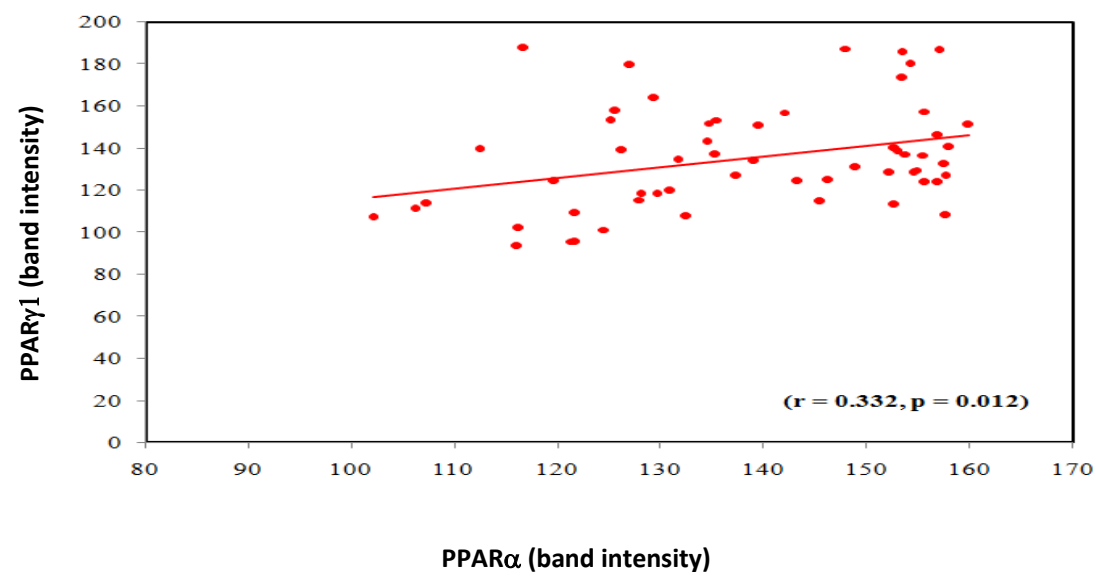

Figure (6): Correlation between gene expression of muscle PPAR $\square$ and gene expression of muscle PPAR $\square 1$ 


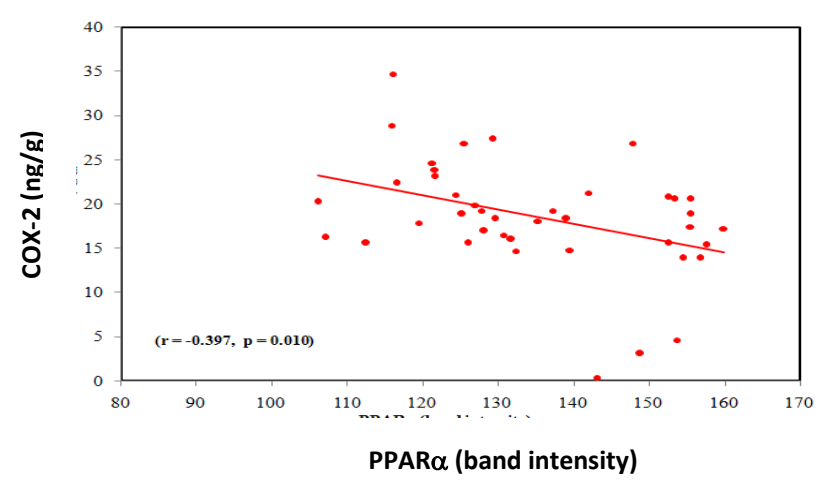

Figure (7): Correlation between gene expression of muscle PPAR $\square$ andCOX-2

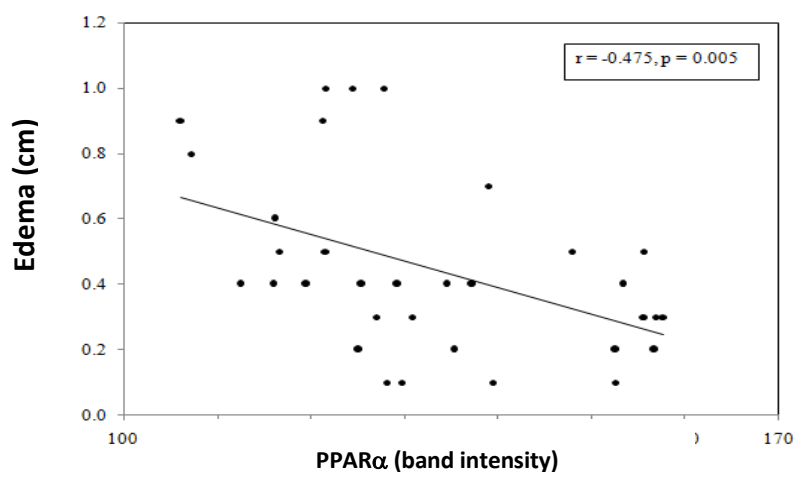

Figure (8): Correlation between gene expressions of muscle PPAR $\alpha$ and edema

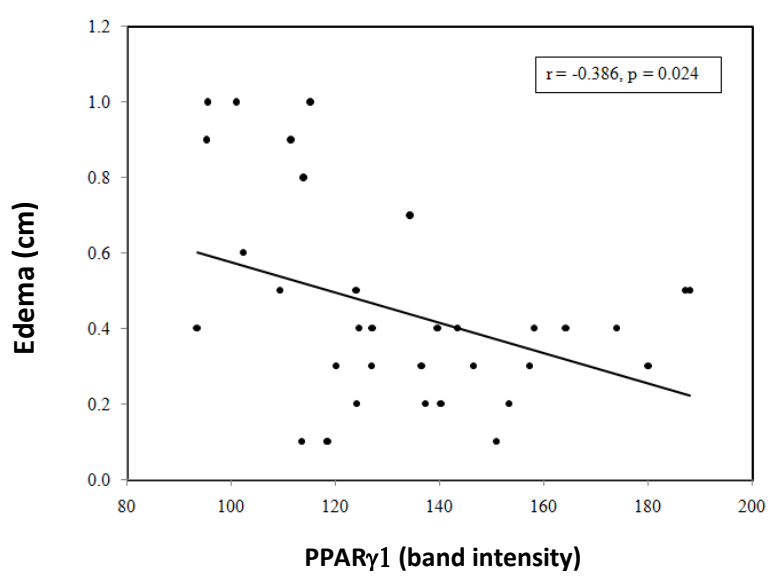

Figure (9): Correlation between gene expressions of muscle PPAR $\gamma 1$ and edema 


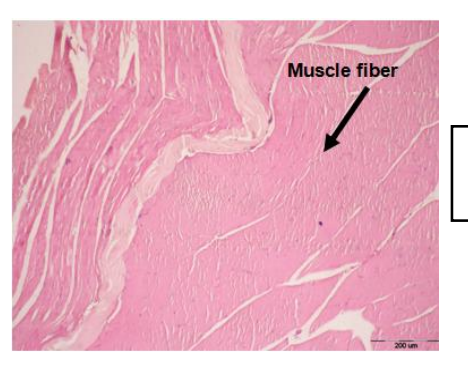

A. Rat muscle of control group showing normal muscle fibers (single arrow) and no inflammation (H\&E X400).

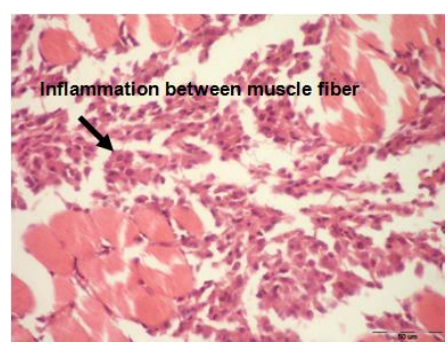

B. Rat muscle of carrageenan group showing moderate $(++)$ to severe $(+++)$ inflammation in between the muscle fibers in the form of leukocytes and dilatation in blood vessels (H\&E X400).

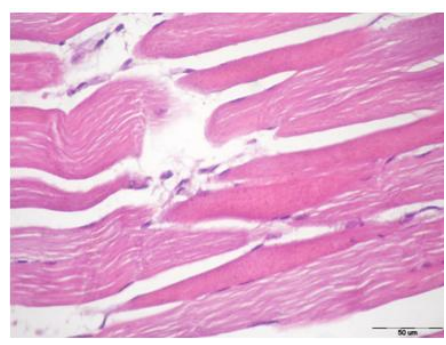

C. Rat muscle of Celecoxib group showing mild (+) inflammation in between the muscle fibers. The muscle fibers are normal without necrosis (H\&E X400).

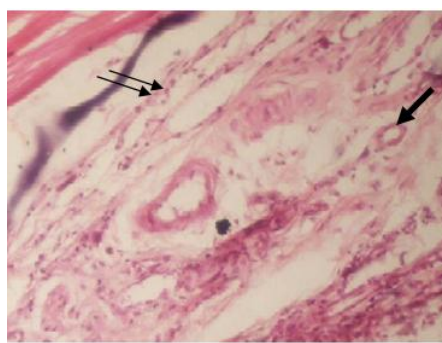

D. Rat muscle of Nimesulide group showing mild $(+)$ to moderate $(++)$ inflammation with granulation tissue formation (double arrows), and newly formed blood vessels (single arrow). The muscle is intact without necrosis (H\&E X400).

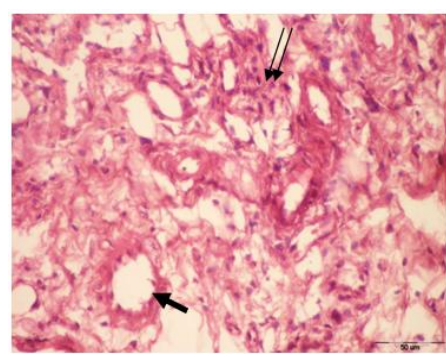

E. Rat muscle of Sulindac group showing moderate $(++)$ to severe $(+++)$ inflammation, infiltrate of inflammatory cells (double arrows) in between muscle fibers, thickening in blood vessels and vascular proliferation (single arrow) (H\&E X400).

Figure (10): Photomicrographs showing histopathological changes of rat muscle

\section{Discussion}

PPAR $\alpha$ and PPAR $\gamma$ activators have been shown to induce differentiation, inhibit proliferation and regulate apoptosis in cancer cells (17). PPAR $\alpha$ had been proven to have anti-inflammatory and anticarcinogenic action (18). More recent evidence implied an important role for the nuclear hormone receptor PPAR $\gamma$ in controlling various diseases based on its anti-inflammatory, cell cycle arresting, and proapoptotic properties (19).

The present study was conducted to elucidate the molecular mechanism of some NSAIDs, as selective and nonselective COX inhibitors, on gene expression of PPAR $\alpha$ and PPAR $\gamma 1$ as well as COX-2 level in a rat model of chronic inflammation.

The present results showed that injection of carrageenan into the gastrocnemius muscle of rats three times per week produced edema with severe inflammation and histological changes in muscle fibers. Moderate to severe inflammation was observed in the form of leukocyte infiltration and dilatation of blood vessels. These 
Gene expression of peroxisome proliferator-activated receptor is upregulated by nonsteroidal anti-

findings were in agreement with (9), who reported that carrageenan can be used as a model of chronic inflammatory hyperalgesia after 1-2 weeks. The carrageenan-induced inflammatory response has been linked to neutrophil infiltration and the production of neutrophil-derived free radicals, such as superoxide, hydroxyl radicals and hydrogen peroxide (20).

Administration of NSAIDs to carrageenan-treated rats decreased the severity of inflammation and reduced edema formation. The anti-inflammatory activity of the selected NSAIDs was arranged in the following descending order; Celecoxib > Nimesulide > Sulindac. The histological results supported these results. The NSAIDs exerted an anti-inflammatory effect where the muscles of rats showed mild inflammation in Celecoxib group, mild to moderate inflammation in Nimesulide group, and moderate to severe inflammation in Sulindac group.

The present results were in agreement with (21), who reported that Celecoxib, a selective COX-2 inhibitor, in a dose of $10 \mathrm{mg} / \mathrm{kg}$ was effective in reducing paw edema. (22) stated that Nimesulide is a multifactorial drug in controlling inflammation and pain. The mechanism of anti-inflammatory activity of Nimesulide is related to the preferential inhibition of the production of COX-2 and other inflammatory mediators whose production is controlled by stimulation of cyclic-3, 5'-adenosine monophosphate (cAMP). (23) reported that Sulindac decreased rat paw carrageenan-induced edema formation to some extent but it was not the most effective NSAID tested for this purpose.

Measurement of COX-2 in rat muscle in the present work provided additional support. COX-2 was greatly increased in carrageenan group compared to normal controls. The percent decrease of COX-2 in Celecoxib group was greater than in the Nimesulide group than in the Sulindac group. These results may attribute to that Celecoxib is a selective COX-2 inhibitor, Nimesulide is a preferential selective COX-2 inhibitor and Sulindac is a nonselective COX inhibitor. Although COX-2 level in NSAIDs treated rats was significantly lower than in the carrageenan-untreated group, it remained higher than the normal control values.

(24) reported that injection of carrageenan increased both edema and COX-2 mRNA level. COX-2 is a major contributor to the inflammatory response and cancer progression and is an attractive target for molecular imaging (25). The higher expression of COX-2 in malignant tissues is also related to nuclear factor-kB (NF$\mathrm{kB}$ ), which positively regulates the COX-2 gene. Sulindac and Celecoxib efficiently suppressed the activation and the transcriptional activity of NF-kB, suggesting an anti-inflammatory role for NSAIDs in colorectal cancer (26). COX-2 expression has often been associated with the poor response to chemotherapy. The induction of proliferation arrest, alteration in cell cycle profile, and cell death by Nimesulide could be related to the downregulating effect of blocking COX-2 on cell survival proteins such as VEGF and IL-10 (27).

In the present work, PPAR $\gamma 1$ gene expression in muscle was significantly decreased in carrageenan group compared with control group. Treatment with NSAIDs upregulated PPAR $\gamma 1$, which was significantly increased compared with carrageenan untreated group. Nimesulide and Celecoxib treated rats showed gene expression of PPAR $\gamma 1$ as in the normal controls, whereas in the Sulindac treated group, PPAR $\gamma 1$ gene expression was about 1.4 fold as that in the normal control group. A significant negative correlation was found between PPAR $\gamma 1$ and edema. The expression levels of both PPAR and RXR mRNA have been found to be decreased in animal model with liver inflammation, indicating that PPAR $\gamma$ and RXR agonists may play an important role in response to inflammation and fibrosis (28).

The present results were in line with the reports that the protein expression of PPAR $\gamma$ was upregulated but COX-2 protein expression was downregulated in the Lewis lung carcinoma cells exposed to Celecoxib (29). Another evidence was provided by the findings that Celecoxib and a PPAR $\gamma$ agonist, separately, inhibited COX2 and upregulated PPAR $\gamma$ expression. These effects were paralleled by inhibition of $\mathrm{PGE}_{2}$ synthesis (30). Thus interference of the arachidonic acid pathway and upregulation of PPAR $\gamma$ simultaneously by Celecoxib have demonstrated great promise in cancer chemoprevention and treatment. In contrast, other studies showed that Celecoxib had no significant effect on PPAR $\gamma$ expression in hepatic stellate cells (31).

The upregulation of PPAR $\gamma 1$ by Nimesulide in the present work was confirmed by the work of (32), who found an intense immunohistochemical staining for PPAR- $\gamma$ in tumor tissue sections from Nimesulide-treated group as compared with the negligible expression in control tumor. Our findings also revealed that Sulindac was a potent inducer of PPAR $\gamma 1$ gene expression in carrageenan-treated rat muscle. These results could be explained by the work of (33), who demonstrated that Sulindac sulfide as well as its 2'-des-methyl derivatives are potent inducers of PPAR $\gamma$, as the carboxylic side chain is required for activity; also it was found that non polar and aromatic substituents on the benzylidene ring in Sulindac structure lead to potent PPAR $\gamma$ agonists.

It is generally assumed that inflammatory bowel disease-related carcinogenesis occurs as a result of chronic inflammation. Thus immunomodulation by the PPARs ligands might contribute to inhibition of colitis and colon carcinogenesis. In addition, PPAR $\alpha$ could suppress COX-2 induction (34). Several NSAIDs can bind to PPAR $\alpha$ and PPAR $\gamma$ and are identified as PPAR ligands; thus activation of PPARs could contribute to anti-inflammatory effect of NSAIDs (35).

Our results showed that PPAR $\alpha$ gene expression in muscle was significantly decreased in carrageenanuntreated rats compared with control rat group. Treatment with NSAIDs resulted in significant increase in 
Gene expression of peroxisome proliferator-activated receptor is upregulated by nonsteroidal anti-

PPAR $\alpha$ gene expression compared with carrageenan-untreated group. In Celecoxib, Nimesulide and Sulindac treated rats, the gene expression level of PPAR $\alpha$ was returned to near its normal level in the control group. In addition, PPAR $\alpha$ gene expression showed a significant positive correlation with PPAR $\gamma 1$ gene expression and a significant negative correlation with each of edema and COX-2 level in muscle.

These results were in agreement with (36), who stated that expression of PPAR $\alpha$ was found to be significantly higher in cells treated with higher doses of NSAIDs as Celecoxib, Nimesulide, Sulindac and indomethacin. Thus, PPAR $\alpha$ mediates the cell growth modulatory effects and contributes to the mechanisms underlying the chemopreventive effects of NSAIDs.

The research conducted by (37) revealed that the pro-inflammatory cytokines IL-6, TNF $\alpha$ and IL-1 cause a reduction in the expression of PPAR $\alpha$, and that the decrease in PPAR $\alpha$ expression and function may contribute to the excessive host inflammatory response. It has been documented that treatment with appropriate doses of PPAR $\alpha$ agonists can inhibit inflammatory diseases development (38). The antinociceptive effects of Nimesulide in carrageenan model of inflammatory hyperalgesia may be mediated by PPAR $\alpha(39)$.

\section{Conclusion}

The anti-inflammatory effect of NSAIDs was mediated by upregulation of PPAR $\gamma 1$ and PPAR $\alpha$ genes. Celecoxib showed the highest potency as anti-inflammatory and COX-2 inhibition, whereas Sulindac exhibited the greatest effect as PPAR $\gamma 1$ inducer. NSAIDs could be considered promising candidates for pharmacologic treatment of tumorgenesis.

\section{Acknowledgments}

The authors would like to thank the Pathologist Ebtehal Ahmed Farrag; MSc in Pathology, Medical Technology Center, Medical Research Institute for her cooperation and guidance in executing the histopathological work.

\section{References}

[1] Manabe I (2011): Chronic inflammation links cardiovascular, metabolic and renal diseases. Circ J 75 (12): 2739 - 2748.

[2] Goljan EF (1998): Inflammation and repair. In: Pathology, W.B. Saunders, Philadelphia, pp 38-54.

[3] Franceschelli S, Moltedo O, Amodio G, Tajana G and Remondelli P (2011): In the Huh7 hepatoma cells diclofenac and indomethacin activate differently the unfolded protein response and induce ER stress apoptosis. Open Biochem J 5: 45-51.

[4] Gene E, Calvet X, Moron A and Iglesias ML (2009): Recommendations for the use of anti-inflammatory drugs and indications for gastrointestinal protection in emergency departments. Emergencias 21: 295-300.

[5] Chung JH, Seo AY, Chung SW, Kim MK, Leeuwenburgh C, Yu BP and Chung HY (2008): Molecular mechanism of PPAR in the regulation of age-related inflammation. Ageing Res Rev 7 (2): 126-136.

[6] Huang W and Glass CK (2010): Nuclear receptors and inflammation control: molecular mechanisms and pathophysiological relevance. Arterioscler Thromb Vasc Biol 30 (8): 1542-1549.

[7] Berger JP, Akiyama TE and Meinke PT (2005): PPARs: therapeutic targets for metabolic disease. Trends Pharmacol Sci 26 (5): 244-251.

[8] Kanayama T, Kobayashi N, Mamiya S, Nakanishi T and Nishikawa J (2005): Organotin compounds promote adipocyte differentiation as agonists of the peroxisome proliferator-activated receptor gamma/retinoid X receptor pathway. Mol Pharmacol 67 (3): 766-774.

[9] Radhakrishnan R, Moore SA and Sluka KA (2003): Unilateral carrageenan injection into muscle or joint induces. Pain 104 (3): 567-577.

[10] Peter-Szabo M, Kekesi G, Nagy E, Sziver E, Benedek G and Horvath G (2007): Quantitative characterization of a repeated acute joint inflammation model in rats. Clin Exp Pharmacol Physiol 34 (5-6): 520-526.

[11] Pinheiro RM and Calixto JB (2002): Effect of the selective COX-2 inhibitors, celecoxib and rofecoxib in rat acute models of inflammation. Inflamm Res. 51 (12): 603-610.

[12] Kopff M, Koppf A and Kowalczyk E (2007): The effect of nonsteroidal anti-inflammatory drugs on oxidative/antioxidative balance. Pol Merkur Lekarski 23 (135): 184-187.

[13] Giuliano F and Warner TD (1999): Ex vivo assay to determine the cyclooxygenase selective non steroidal anti-inflammatory drugs. Br J Pharmacol 126 (8): 1824-1830.

[14] Ping YE, Zhao-jun W, Xiu-jin Z and Ya-li Z (2005): Age-related decrease in expression of peroxisome proliferator-activated receptor $\alpha$ and its effects on development of dyslipidemia. Chin Med J (Eng) 118 (13): 1093-1098.

[15] Liu D, Zeng BX and Shang Y (2006): Decreased expression of peroxisome proliferator-activated receptor $\gamma$ in endotoxin-induced acute lung injury. Physiol Res 55 (3): 291-299.

[16] Zhang HX, Wang Q, Zhou L, Liu LG, Yang X, Yang M, Liu YN and Li X (2009): Effects of scalp acupuncture on acute cerebral ischemia-reperfusion injury in rats. Zhong Xi Yi Jie He Xue Bao 7 (8): 769-774. [English Abstract]

[17] Sertznig P, Seifert M, Tilgen W and Reichrath J (2008): Peroxisome proliferator-activated receptors (PPARs) and the human skin: importance of PPARs in skin physiology and dermatologic diseases. Am J Clin Dermatol 9 (1): 15-31.

[18] Meissner M, Berlinski B, Gille J, Doll M and Kaufmann R (2011): Peroxisome proliferator activated receptor- $\alpha$ agonists suppress transforming growth factor- $\alpha$-induced matrix metalloproteinase-9 expression in human keratinocytes. Clin Exp Dermatol 36 (8): 911-914

[19] Schmidt MV, Brüne B, and von Knethen A (2010): The nuclear hormone receptor PPAR $\gamma$ as a therapeutic target in major diseases. ScientificWorldJournal 10: 2181-2197.

[20] Lai S, Peng WH, Huang SC, Ho YL, Huang TH, Lai ZR and Chang YS (2009): Analgesic and anti-inflammatory activities of methanol extract from desmodium triflorum DC in mice. Am J Chin Med 37 (3): 573-588.

[21] Khayyal MT, El-Ghazaly MA, El-Hazek RM and Nada AS (2009): The effects of celecoxib, a COX-2 selective inhibitor, on acute inflammation induced in irradiated rats. Inflammopharmacology 17 (5): 255-266.

[22] Brooks RR, Bonk KR, Decker GE and Miller KE (1985): Anti-inflammatory activity of orpanoxin administered orally and topically to rodents. Agents Actions 16 (5): 369-376. 
Gene expression of peroxisome proliferator-activated receptor is upregulated by nonsteroidal anti-

[23] Rainsford KD (2006): Current status of the therapeutic uses and actions of the preferential cyclo-oxygenase-2 NSAID, nimesulide. Inflammopharmacology 14 (3-4): 120-137.

[24] Albertini R, Aimbire F, Villaverde AB, Silva JA Jr and Costa MS (2007): COX-2 mRNA expression decreases in the subplantar muscle of rat paw subjected to carrageenan-induced inflammation after low level laser therapy. Inflamm Res 56 (6): 228-229.

[25] Uddin MJ, Crews BC, Ghebreselasie K, Huda I, Kingsley PJ, Ansari MS, Tantawy MN, Reese J and Marnett LJ (2011): Fluorinated COX-2 inhibitors as agents in PET imaging of inflammation and cancer. Cancer Prev Res (Phila) 4 (10): 1536-1545.

[26] Vaish V and Sanyal SN (2011): Chemopreventive effects of NSAIDs on cytokines and transcription factors during the early stages of colorectal cancer. Pharmacol Rep 63 (5): 1210-1221.

[27] Paul AG, Sharma-Walia N and Chandran B (2011): Targeting KSHV/HHV-8 latency with COX-2 selective inhibitor nimesulide: a potential chemotherapeutic modality for primary effusion lymphoma. PLoS One 6 (9): 1-19.

[28] Yamamoto A, Kakuta H, Miyachi H and Sugimoto Y (2011): Involvement of the retinoid X receptor ligand in the antiInflammatory effect induced by peroxisome proliferator-activated receptor $\gamma$ agonist in vivo. PPAR Res 2011: 1-8.

[29] Zhang M, Xu ZG, Shi Z, Shao D, Lio O, Li W, Li ZJ, Wang KZ and Chen L (2011): Inhibitory effect of celecoxib in lung carcinoma by regulation of cyclooxygenase-2/cytosolic phospholipase $A_{2}$ and peroxisome proliferator-activated receptor gamma. Mol Cell Biochem 355 (1-2): 233-240.

[30] Badawi AF, Eldeen MB, Liu Y, Ross EA and Badr MZ (2004): Inhibition of rat mammary gland carcinogenesis by simultaneous targeting of cyclooxygenase-2 and peroxisome proliferator-activated receptor $\gamma$. Cancer Res 64 (3): 1181-1189.

[31] Paik YH, Kim JK, Lee JI, Kang SH, Kim DY, An SH, Lee SJ, Lee DK, Han KH, Chon CY, Lee SI, Lee KS and Brenner DA (2009): Celecoxib induces hepatic stellate cell apoptosis through inhibition of Akt activation and suppresses hepatic fibrosis in rats. Gut 58 (11): 1517-1527.

[32] Shaik MS, Chatterjee A and Singh M (2004): Effect of a selective cyclooxygenase-2 inhibitor, nimesulide, on the growth of lung tumors and their expression of cyclooxygenase- 2 and peroxisome proliferator activated receptor- $\gamma$. Clin Cancer Res 10 (4): $1521-$ 1529.

[33] Felts AS, Siegel BS, Young SM, Moth CW, Lybrand TP, Dannenberg AJ, Marnett LJ and Subbaramaiah K (2008): Sulindac derivatives that activate the peroxisome proliferator-activated receptor $\gamma$ but lack cyclooxygenase inhibition. J Med Chem 51: 49114919.

[34] Kohno H, Suzuki R, Sugie S and Tanaka T (2005): Suppression of colitis-related mouse colon carcinogenesis by a COX-2 inhibitor and PPAR ligands. BMC Cancer 5 (46): 1-12.

[35] Michalik L, Auwerx J, Berger JP, Chatterjee VK, Glass CK, Gonzalez FJ, Grimaldi PA, Kadowaki T, Lazar MA, O'rahilly S, Palmer C, Plutzky J, Reddy JK, Spiegelman BM, Staels B and Wahli W (2006): International union of pharmacology. LXI. peroxisome proliferator-activated receptors. Pharmacol Rev 58 (4): 726-741.

[36] Foreman JE, Sorg JM, McGinnis KS, Rigas B, Williams JL, Clapper ML, Gonzalez FJ and Peters JM (2009): Regulation of peroxisome proliferator-activated receptor- $\beta / \delta$ by the APC/ $\beta$-catenin pathway and nonsteroidal anti-inflammatory drugs. Mol Carcinog 48 (10): 942-952.

[37] Reynders V, Loitsch S, Steinhauer C, Wagner T, Steinhilber D and Bargon J (2006): Peroxisome Proliferator-Activated Receptor $\alpha$ (PPAR $\alpha$ ) down-regulation in cystic fibrosis lymphocytes. Respir Res 7 (104): 1-15.

[38] Crisafulli C, Bruscoli S, Esposito E, Mazzon E, Di Paola R, Genovese T, Bramanti P, Migliorati G and Cuzzocrea S (2009): PPARalpha contributes to the anti-inflammatory activity of 17-beta-estradiol. J Pharmacol Exp Ther 331 (3): 796-807.

[39] Jhaveri MD, Richardson D, Robinson I, Garle MJ, Patel A, Sun Y, Sagar DR, Bennett AJ, Alexander SP, Kendall DA, Barrett DA and Chapman V (2008): Inhibition of fatty acid amide hydrolase and cyclooxygenase-2 increases levels of endocannabinoid related molecules and produces analgesia via peroxisome proliferator-activated receptor-alpha in a model of inflammatory pain. Neuropharmacology 55 (1): 85-93. 